\title{
Desafios e barreiras ao aplicar as TIC's no processo de ensino e aprendizagem
}

\author{
OLIVEIRA, Renata Tognon Rinco ${ }^{1}$ \\ ALVES, Andressa Giarola²
}

\section{RESUMO}

O presente trabalho de pesquisa tem como tema o uso das novas Tecnologias de Informação e Comunicação no contexto do que chamamos de Ensino Regular. Algumas ideias e pensamentos foram discutidos quanto ao uso das ferramentas tecnológicas, quais as principais dificuldades encontradas pelos professores na utilização, qualidade e a quantidade dos recursos repassados para as escolas e também analisamos quais os desafios enfrentados pelos profissionais da educação em relação ao uso da tecnologia através de uma pesquisa de campo realizada com educadores de escolas municipais e estaduais da cidade de Cláudio estado de Minas Gerais. Proporcionando reflexões e discussões sobre a aceitação e o domínio dos profissionais da educação quanto ao uso das novas tecnologias educacionais. Para finalizar o trabalho foi possível entender que as novas tecnologias estão presentes no contexto escolar com intuito de auxiliar a aprendizagem.

Novas Tecnologias. Resistência. Ensino e Aprendizagem.

\section{Challenges and barriers when applying ICT's in the teaching and learning process}

\section{ABSTRACT}

This research has as its theme the use of new Information and Communication Technologies in the context of what we call Regular Education. Some ideas and thoughts were discussed about the use of technological tools, what are the main difficulties teachers find in using, quality and the amount of resources passed on to schools and we also analyzed what are the challenges faced by education professionals regarding the use of technology. through a field research conducted with educators of municipal and state schools of the city of Cláudio state of Minas Gerais. Providing reflections and

\footnotetext{
${ }^{1}$ Graduada em Ciências Biológicas pelo Instituto Federal de Educação, Ciência e Tecnologia de Minas Gerais - IFMG e especialização em Ciências da Educação: Tecnologias na Educação pelo Instituto Federal de Educação, Ciência e Tecnologia de Minas Gerais, Arcos. E-mail: renatarinco_@hotmail.com. Lattes: http://lattes.cnpq.br/5105785775276889. ORCID: https://orcid.org/0000-0001-9143-6405.

2 Mestra em ensino de Física E-mail: andressagiarola@gmail.com. Lattes:

http://lattes.cnpq.br/2080487339146515. ORCID: https://orcid.org/0000-0003-0895-7897.
} 
discussions about the acceptance and mastery of education professionals regarding the use of new educational technologies. To finish the work it was possible to understand that the new technologies are present in the school context in order to help the learning.

New Technologies. Resistance. Teaching and Learning.

\section{Desafíos y barreras al aplicar las TIC en el proceso de enseñanza y aprendizaje}

\section{RESUMEN}

Este trabajo de investigación tiene como tema el uso de nuevas tecnologías de información y comunicación en el contexto de lo que llamamos Enseñanza Regular. Se discutieron algunas ideas y pensamientos sobre el uso de herramientas tecnológicas, cuáles son las principales dificultades que enfrentan los docentes en el uso, la calidad y la cantidad de recursos transferidos a las escuelas y también analizamos cuáles son los desafíos que enfrentan los profesionales de la educación en relación con el uso de la tecnología a través de una investigación de campo realizada con educadores de escuelas municipales y estatales en la ciudad de Cláudio, provincia de Minas Gerais. Brindando reflexiones y debates sobre la aceptación y el dominio de los profesionales de la educación sobre el uso de las nuevas tecnologías educativas. Para concluir el trabajo, fue posible comprender que las nuevas tecnologías están presentes en el contexto escolar para facilitar el aprendizaje.

Nuevas tecnologías. Resistencia. Enseñanza y aprendizaje.

\section{Sfide e ostacoli nell'applicazione delle TIC nel processo di insegnamento e apprendimento}

\section{SINTESE}

Questo lavoro di ricerca ha come tema l'uso di nuove tecnologie di informazione e comunicazione nel contesto di ciò che chiamiamo insegnamento regolare. Sono state discusse alcune idee e riflessioni sull'uso degli strumenti tecnologici, quali sono le principali difficoltà che gli insegnanti affrontano nell'uso, nella qualità e nella quantità delle risorse trasferite nelle scuole e analizziamo anche quali sono le sfide che i professionisti devono affrontare nel educazione in relazione all'uso della tecnologia attraverso un'indagine sul campo condotta con educatori delle scuole comunali e statali della città di Cláudio, provincia di Minas Gerais. Fornire riflessioni e dibattiti sull'accettazione e la padronanza dei professionisti dell'educazione sull'uso delle nuove tecnologie educative. Per concludere il lavoro, è stato possibile capire che le nuove tecnologie sono presenti nel contesto scolastico per facilitare l'apprendimento.

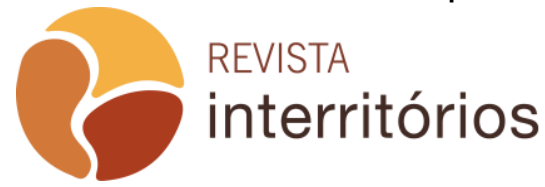

Interritórios | Revista de Educação Universidade Federal de Pernambuco, Caruaru, BRASIL | V.6 N.10 [2020] 
Nuove tecnologie. Resistenza. Insegnare e impare.

\section{INTRODUÇÃO}

O fim do século XX foi marcado por muitas mudanças, no âmbito político, social e econômico. Nesse mesmo período houve a implantação das Tecnologias em vários setores, devido principalmente ao Capitalismo. Assim, segundo Belloni (2001) a escola se tornou um alvo receptor das Novas Tecnologias de Informação e Comunicação, através de ações criadas pelo Estado por meio das chamadas políticas públicas.

À medida que surgem novas tecnologias, os setores sejam eles na área da educação ou qualquer outra, vão aderindo a esses meios como forma de facilitar o trabalho feito pelo ser humano. Assim, é certo afirmar que a tecnologia tem um papel importante na vida escolar tanto na colaboração do trabalho realizado pelos profissionais que ali estão, quanto a facilidade proporcionada por ela na aprendizagem dos educandos ao utilizarem tais ferramentas.

Por isso, é viável um estudo e análise sobre o uso de novas tecnologias no processo de ensino e aprendizagem dentro do Ensino Regular brasileiro e como os educadores lidam com essa questão dentro da sala de aula e na forma de ensinar, pois, no ambiente escolar evidencia-se a falta de correspondência às mudanças contemporâneas por parte de alguns educadores, e isso pode ser um ponto negativo ao pensarmos que as tecnologias têm apresentado grande potencial no auxílio das práticas pedagógicas quando usadas em sala de aula para fins didáticos da forma adequada.

Quanto ao setor educacional o problema atual em relação a essas ferramentas é o despreparo por parte de alguns educadores que atuam nas escolas. Alguns ainda não se acostumaram com a ideia de ter seus alunos usando, por exemplo, um celular em sala de aula para realizar uma simples pesquisa sobre determinado tema, isso porque nos últimos anos o celular tem causado alguns transtornos para os professores. Outros entendem que o uso das Novas Tecnologias de Informação e Comunicação é ideal, mas infelizmente grande parte das escolas não contam com serviços de qualidade para dar assistência aos educadores e educandos, além da grande quantidade de profissionais da educação, já citado, que não aceitam as novas tecnologias como instrumento transformador na prática pedagógica.

Dessa forma, o objetivo geral do trabalho em questão é realizar um apanhado sobre o tema do uso das Novas Tecnologias na Educação Regular, para suporte a

REVISTA interritórios
Interritórios | Revista de Educação Universidade Federal de Pernambuco, Caruaru, BRASIL | V.6 N.10 [2020] 
pesquisa de campo. Já os objetivos específicos serão a contextualização do tema, compreendendo um pouco sobre o que se tratam as TIC's; a coleta de informações por meio de entrevistas através de questionários durante a pesquisa de campo e entender os desafios enfrentados pela educação na tentativa de uso das ferramentas tecnológicas que hoje estão presentes em todos os ambientes. A referida pesquisa tem subsídios teóricos baseados em pesquisa na internet, livros e trabalhos científicos e traçará as ideias sobre o uso de novas Tecnologias de Informação e Comunicação para facilitar a vida da comunidade escolar.

O questionário aplicado na pesquisa busca verificar se a educação é trabalhada pelos professores do município de Cláudio em Minas Gerais por meio da informatização, se implementam ou não os recursos tecnológicos nas suas práticas pedagógicas e como é realizado.

\section{Referencial Teórico}

Contextualização do Tema

Em cada período histórico temos a criação de tecnologias de informação, cada uma foi considerada moderna se levarmos em conta a época em que foi inventada. $O$ telégrafo, por exemplo, foi algo moderno e inovador, hoje já não tem utilidades. Para os novos tempos, o que mais causou impacto em termos de Novas Tecnologias de Informação e Comunicação foi o advento da Internet no século XX, e o sentido de navegar por ela para obter informações através de sites de buscar usando o World Wide Web (WWW). Hoje, contamos com a existência de programas indicados às mais diversas áreas dentre elas a educacional.

As tecnologias na educação não são algo recente, desde o uso do quadro e giz já eram considerados uma tecnologia. Entretanto, quando pensamos na resistência que alguns educadores têm em utilizar as novas tecnologias de informação e comunicação descobrimos que essa rejeição muitas vezes se dá devido à falta de conhecimento sobre as ferramentas tecnologias, por parte desses, e a forma metodológica utilizada para adquirir praticidade no processo de ensino/aprendizagem. Embora a tecnologia seja algo presente na vida do ser humano e muitas vezes indispensável, a relutância desses profissionais da educação para Nunes e Gallota (2011) é resultado não só da falta de preparo, mas também falta de direcionamento por parte da escola.

REVISTA

interritórios
Interritórios | Revista de Educação Universidade Federal de Pernambuco, Caruaru, BRASIL | V.6 N.10 [2020] 
É necessário que os profissionais da educação consigam dominar as novas tecnologias para que alcance uma evolução mais rápida e eficaz no que se diz respeito ao ensino/aprendizagem dos educandos. Existem diversos benefícios que as TIC's são capazes de fornecer aos profissionais da educação em auxílio das práticas pedagógicas, neste viés, Martinho Pombo (2009) discute que,

As tecnologias de informação e comunicação (TIC) podem constituir um elemento valorizador das práticas pedagógicas, já que acrescenta em termos de acesso à informação, flexibilidade, diversidades de suportes no seu tratamento e apresentação. Valorizam, ainda, os processos de compreensão de conceitos e fenômenos diversos, na medida em que conseguem associar diferentes tipos de representação que vão desde o texto, à imagem fixa e animada, ao vídeo e ao som [...]. (MARTINHO, POMBO, 2009, p. 528).

Visando, claro, que a Escola também tem a responsabilidade de prover 0 conhecimento de como utilizar a tecnologia escolhida através de cursos e outros, também deve assumir a responsabilidade de produzir uma visão crítica das mesmas, e os professores precisam estar conscientes disto.

É importante ressaltar que se tratando de políticas sociais de implementação, a escola sempre contou com suas políticas educacionais a favor da priorização do atendimento aos alunos e professores. Através do Ministério da Educação, o Brasil tem registrado uma história relacionada a investimentos em vários projetos de tecnologias educacionais. O que deu início a necessidade de se consumir novas tecnologias para fins educativos. É por isso que o tema Tecnologias da Informação e da Comunicação encontram-se presentes nas Diretrizes Curriculares Nacionais para a Educação Básica, e devem ser consideradas em práticas pedagógicas.

As tecnologias sempre estiveram a favor da educação, um exemplo citado por Niskier (1993) foi a Tele Educação e o Tele Curso do $2^{\circ}$ que surgiu em 1977. Ainda no final da década de 1970, têm-se os cursos de informática que foram levados as escolas por meio do projeto Educação com Computador (EDUCOM); A TV ESCOLA, Programa da Secretaria de Educação a Distância, promovido pelo Ministério da Educação criado em 1995; O PROINFO - Programa Nacional de Tecnologia Educacional criado em 09 de abril de 1997, pelo Ministério da Educação, entre muitos outros. Tais ações são modelos de Tecnologia de Informação e Comunicação sendo integradas no ambiente escolar.

É importante ressaltar que nenhuma tecnologia leva a aprendizagem sem a participação do principal papel, o professor. Atualmente enfrentamos o receio desses profissionais da educação serem substituídos, por exemplo, pelo computador. "Uma das soluções para esse impasse está na possibilidade de educadores também participarem

REVISTA

interritórios
Interritórios | Revista de Educação Universidade Federal de Pernambuco, Caruaru, BRASIL | V.6 N.10 [2020] 
das equipes produtoras dessas novas tecnologias educativas." (KENSKI, 2012, p. 49-50) e a capacitação desses profissionais em cursos intensivos. Somente assim, o professor continuará se sentindo parte importante da escola e indispensável. Ressalta-se que juntamente à preparação do professor, deve-se levar em conta a estrutura da escola para o recebimento das tecnologias educacionais as instalações em salas readaptadas.

\section{O Professor e a Tecnologia}

O trabalho docente é uma ação que sofre e passa por constates mudanças organizacionais, curriculares, extracurriculares, entre outras, estas mudanças exigem dos professores novos papéis e novas competências. Integrar as tecnologias como apoio ao ensino aprendizagem se encaixa dentro dessas mudanças e é um grande desafio para a educação, especialmente na rede pública de ensino para dar igualdade de condições aos educandos.

Pensando nesse sentido, existe a possibilidade de se elaborar atividades utilizando-se os computadores ou outra ferramenta tecnológica como meio de contextualização do assunto, possibilitando que o educando aprenda conceitos que são classificados difíceis.

Existem atividades educacionais por meio do uso de computadores que são muito boas para motivar ou contextualizar um novo assunto a ser tratado, outros ótimas para visualizar conceitos complexos, algumas que induzem o aluno a certos pensamentos, outros ideais para uma aplicação inteligente do que estão aprendendo. Quando as atividades são interativas, consegue-se que o aluno tenha um papel bastante ativo. Permite-se ainda que o aluno se aproprie da atividade e a utilize inserindo em seus próprios trabalhos para comentários, ilustrações, críticas e assim consegue-se uma aprendizagem ainda mais significativa. (NUNES; GALLOTA, 2011).

Esse é o principal ponto em que o docente deve ponderar antes de usar as Tecnologias de Informação e Comunicação. A aprendizagem deve ser significativa para o educando, ou seja, que ele possa adquirir mais conhecimentos do que se estivesse aprendendo o assunto apenas com o livro didático ou com atividades escritas no quadronegro, por exemplo.

Cavalcante (2012) ressalta que trabalhar com tecnologias é indispensável para o desenvolvimento contínuo tanto do educando quanto do educador. Almeida e Vicente

REVISTA interritórios
Interritórios | Revista de Educação Universidade Federal de Pernambuco, Caruaru, BRASIL | V.6 N.10 [2020] 
(2008) entendem que ao contextualizar o conteúdo do livro em ferramentas midiáticas, o professor complementará seu método de ensino, dando ao aluno a oportunidade de ter ferramentas didáticas modernas que facilitem a busca pelo tema em caso de dúvidas. "O computador passou a assumir um papel fundamental de complementação, de aperfeiçoamento e de possível mudança na qualidade da educação, possibilitando a criação de ambientes de aprendizagem." (ALMEIDA; VALENTE, 2008, p.05). Além de outros vários tipos de ferramentas tecnológicas que podem ser inseridas para que tenham essa mesma finalidade, hoje em dia é muito comum que um aluno possua um notebook (computador portátil) ou tablet.

Nota-se que esse mundo de novas possibilidades e desafios é algo que será trabalho pelo educador, que se apresentará como o sujeito responsável por manter o equilíbrio em sala de aula, seja no uso do livro, do caderno, do quadro, do computador ou de qualquer outra ferramenta a ser utilizada para a aula em questão.

Quando se pensa em mudanças de espaços na escola para o aluno interagir, as novas tecnologias se encontram presentes. Não há como se pensar em algo novo que não esteja diretamente relacionado às TIC's.

Desafios e Barreiras

Poderíamos falar de vários desafios a serem enfrentados nas escolas brasileiras hoje em dia, principalmente nas públicas. Dentro do tema em questão optamos por escolher duas questões importantes: quais são as principais dificuldades encontradas pelos professores na utilização desses recursos tecnológicos em suas práticas e a qualidade e a quantidade de recursos repassados para as escolas de ensino público. Além da questão da infraestrutura, as escolas, principalmente as públicas muitas vezes não se encontram devidamente adaptadas para receber equipamentos midiáticos, ou seja, não possuem salas preparadas para manter essas tecnologias e em muitos casos sem segurança também. "O primeiro desafio está relacionado às inovações presentes nos recursos tecnológicos, que têm surgido de forma mais rápida do que a capacidade de absorção pela grande maioria da população mundial, especialmente a brasileira." (FRANCO; ALMEIDA, 2013, p. 49).

Ainda de acordo com Franco e Almeida (2013) as escolas brasileiras, contam com duas formas de políticas federais de distribuição de tecnologias educacionais. A primeira é através do MEC ou demandas políticas e a segunda se refere a formação de professores para o aprimoramento das habilidades desses profissionais para que

REVISTA interritórios
Interritórios | Revista de Educação Universidade Federal de Pernambuco, Caruaru, BRASIL | V.6 N.10 [2020] 
possam usar as novas ferramentas tecnológicas que forem disponibilizadas nas escolas.

Dessa forma, já é possível notar que há uma preocupação por parte das políticas públicas em levar tecnologias às escolas e ao mesmo tempo há a preocupação de preparar os profissionais da educação para isso.

No entanto, é importante ressaltar que as novas tecnologias sem didática e planejamento não são capazes de trazer todo o conhecimento que os educandos necessitam. (KENSKI, 2012). O professor deve estar preparado para mesclar os conteúdos presentes nos livros didáticos com as TIC'S, ou seja, usar uma ferramenta tecnológica em sala de aula deverá ser algo para um determinado fim em um momento específico da aula, não devendo ser o ponto principal e não deve tomar grande parte do tempo disponível que o educador tem para transmitir o conhecimento a seus alunos. "Interagir com as informações e com as pessoas para aprender é fundamental." (KENSKI, 2012, p.122).

Os professores diante desse pensamento de Kenski passam a se questionar sobre o uso das novas tecnologias simplesmente porque acreditam que para aprender, em sua época, não foi necessário o uso da Internet ou de recursos didáticos que precisassem de uma rede que pudesse fornecer informações rápidas aos alunos.

Outro ponto que também é bastante questionado pelos educadores é a questão do uso monitorado da Internet em sala. É preciso um total controle sobre o que o aluno está pesquisando, que tipo de site ele está tendo acesso enquanto o docente explica e executa a atividade proposta, sendo prudente uma pesquisa antecipadamente para o direcionamento de um site conhecido pelo docente e que vá atender a aula planejada. $O$ que alguns educadores não compreendem é que o termo "tecnologia de informação" não se refere somente a algo novo.

A forma como organizamos em grupo, em salas, em outros espaços: isso também é tecnologia. O giz que escreve na lousa é tecnologia de comunicação, e uma boa organização de escrita facilita - muito - a aprendizagem. A forma de falar, gesticular, de falar com os outros: isso também é tecnologia. O livro, a revista, o jornal, o gravador, o retroprojetor, a televisão, o vídeo são tecnologias importantes e muito mal utilizadas em geral. (MORAN; MASETTO; e BEHRENS, 2003, p.153).

Ou seja, a tecnologia em sala de aula está associada a como o professor faz uso da mesma e não que tipo de tecnologia ele terá que usar. Claro que em um mundo globalizado é normal que os alunos indaguem o professor sobre a possibilidade de usar novas tecnologias, alguns livros didáticos também já contem atividades que pedem o uso de pesquisas em links direcionados a Internet. Tais atividades deixam o aluno mais

REVISTA interritórios
Interritórios | Revista de Educação Universidade Federal de Pernambuco, Caruaru, BRASIL | V.6 N.10 [2020] 
animado e o professor não pode perder essa oportunidade de tornar a aula mais dinâmica e ao mesmo tempo divertida.

No entanto, vale ressaltar que o uso das TIC's só é viável se as mesmas trouxerem resultados positivos e satisfatórios durante a exposição do conteúdo. É o que prevê os Parâmetros Curriculares Nacionais do terceiro e quarto ciclos: "Só tem sentido se contribuir para a melhoria da qualidade do ensino." (BRASIL, 1998, p.140).

Fatin (2007, p. 04) afirma que: "é possível educar integrando mídia e educação [...] ou seja, com o apoio de ferramentas tecnológicas disponíveis como: computador, Internet, celular, vídeos, CDs, DVDs, somado a livros, fotografias, cinema, ente outros, integrando com a corporeidade, a expressividade, o teatro, a dança, etc." Dessa forma, podemos pensar em uma educação com uso de tecnologias, ainda que muitas escolas não tenham uma equipagem completa.

Trata-se, pois, de um ensino e aprendizagem cooperativa em que o educando terá ajuda de ferramentas midiáticas, junto aos livros didáticos e as competências adquiridas por ele ao longo dos seus anos de estudos e dedicação à docência. É por isso que Lévy (2005) entende que:

Não se trata aqui de utilizar as tecnologias a qualquer custo, mas sim de acompanhar consciente e deliberadamente uma mudança de civilização que questiona profundamente as formas institucionais, as mentalidades e a cultura dos sistemas educacionais tradicionais e, sobretudo, os papéis de professor e de aluno. (LÉVY, 2005, p. 172).

Assim, é preciso a formação de docentes que estejam preparados para essas novas demandas de alunos necessitados do consumo de tecnologias. Ter um celular em sala de aula é uma realidade que já não pode ser modificada, apenas aprimorada a favor da educação.

O professor sempre será o profissional preparado para mediar e guiar alunos em direção à educação. Os alunos, por sua vez, devem estar conscientes do papel e função do professor, sendo acompanhados e instruídos sempre pelo mesmo para que possam adquirir conhecimento por meio das Novas Tecnologias. "A inserção nos espaços de convivência da cultura digital apresenta um encantamento próprio provocado pela ampliação dos universos culturais e das relações sociais e emocionais que são nela estabelecidas." (FRANCO; ALMEIDA, 2013, p. 50).

Mesmo com investimentos e disponibilidade por parte do Estado em oferecer para os educadores uma formação continuada ou cursos de aperfeiçoamento, a realidade do professor brasileiro não dá a ele a oportunidade de aproveitar tais benefícios. O que

REVISTA interritórios
Interritórios | Revista de Educação Universidade Federal de Pernambuco, Caruaru, BRASIL | V.6 N.10 [2020] 
temos hoje são professores sem o devido preparado para estar diante da tarefa de incluir em suas atividades as novas tecnologias junto com a resistência em assumir esse novo compromisso.

Carvalho (2004) atenta para a questão que deixa o professor em estado de desespero. Professores sem preparo se recusam a trabalhar com o novo. Tal problema ocorre devido à falta de formação continuada, pois muitos educadores não tem um retorno financeiro que possam direcionar para a continuação dos estudos, através de uma especialização ou pós-graduação, por exemplo. "O salário médio de nossos professores é muito baixo dificultando-lhes a aquisição de livros, assinaturas em revistas de educação, ou a frequência em cursos." (CARVALHO, 2004, p 113).

Esse e outros fatores são suficientes para que o professor opte por começar a trabalhar assim que conclui a graduação, deixando a especialização para outro momento, mesmo sabendo que uma capacitação ou uma pós-graduação é o primeiro passo para um diferencial e consequentemente consiga o êxito almejado na profissão.

Também há aqueles professores mais velhos que atuam em sala de forma ultrapassada porque já não tem interesse em modernizar os seus métodos de ensino. (MORAN; MASETTO; BEHRENS, 2003). São profissionais bons, mas que se recusam a entender a importância do uso de Novas Tecnologias de Informação e Comunicação.

Para nós, professores, essa mudança de atitude não é fácil. Estamos acostumados e sentimo-nos seguros com o nosso papel de comunicar e transmitir algo que conhecemos muito bem. Sair dessa posição, entrar em diálogo direto com os alunos, correr risco de ouvir uma pergunta para a qual no momento talvez não tenhamos resposta, e propor aos alunos que pesquisemos juntos para buscarmos resposta - tudo isso gera um grande desconforto e uma grande insegurança. (MORAN; MASETTO, BEHRENS, 2003, p.142).

Por isso a importância de uma formação continuada ou até mesmo uma capacitação em cursos, dentro da própria escola, oferecidos a estes professores para que eles resgatem a vontade de ensinar sempre buscando inovar.

De acordo com Papert (1985) essa formação continuada não só se trata de um treinamento como também de algo com que o professor irá se beneficiar e consequentemente aos alunos. Assim, têm-se as Diretrizes Curriculares Nacionais para a Formação de Professores da Educação Básica que instituem "o uso de tecnologias da informação e da comunicação e de metodologias, estratégias e materiais de apoio inovadores." (BRASIL, 2002).

No curso oferecido pelo MEC/SEED, por exemplo, o professor poderá contar com

REVISTA interritórios
Interritórios | Revista de Educação Universidade Federal de Pernambuco, Caruaru, BRASIL | V.6 N.10 [2020] 
uma capacitação que oferece inicialmente a sensibilização e motivação das escolas para incorporação das TIC's; também oferece apoio ao processo de planejamento tecnológico das escolas para aderirem ao projeto de informática na educação; em seguida oferece a capacitação dos professores e também das equipes administrativas das escolas; depois a realização de cursos especializados para as equipes de suporte técnico; o apoio para solução de problemas técnicos decorrentes do uso do computador nas escolas; e, por fim, assessoria pedagógica para uso da tecnologia no processo de ensino e aprendizagem com acompanhamento e avaliação local do processo de informatização das escolas.

Dentro do que foi apresentado, é possível chegar ao entendimento de que as novas Tecnologias de Informação e Comunicação são significativas quando integradas em um contexto estrutural de mudança do ensino-aprendizagem, em que professores e alunos vivenciem processos de comunicação abertos, pois tais tecnologias não modificam sozinhas o processo de ensinar e aprender.

\section{Metodologia}

Através de levantamento bibliográfico, foram analisados livros e textos de vários autores, que discutem sobre a utilização das tecnologias na educação. Em sequência à realização de todo esse estudo bibliográfico, foi realizada uma pesquisa com o intuito de investigar se na cidade de Cláudio estado de Minas Gerais existem barreiras para o uso das ferramentas tecnológicas, quais as dificuldades mais frequentes e quais os possíveis fatores que levam a resistência ao uso das TIC's no ambiente escolar. Os sujeitos da pesquisa são professores que atuam na rede municipal e estadual de ensino da cidade de Cláudio e que lecionam para alunos do ensino fundamental e médio.

O desenrolar da pesquisa deu-se em etapas: Primeira etapa a revisão bibliográfica sobre o uso das TIC's e os desafios dos professores como sustentação ao trabalho. Segunda etapa realizou-se uma pesquisa de cunho qualitativo, utilizando-se um questionário semiestruturado contendo questões mistas, a fim de obter a opinião de profissionais da educação que estão em sala de aula. Terceira etapa a organização e análise dos dados coletados.

O questionário foi realizado com a participação de 8 professores atuantes na educação e é estruturado pela identificação composta por quatro perguntas relacionadas a faixa etária, ao sexo, a escolaridade e a área de atuação. E outras cinco relacionadas a questões sobre a vivência com as ferramentas tecnológicas em seu cotidiano, em casa

REVISTA

interritórios
Interritórios | Revista de Educação Universidade Federal de Pernambuco, Caruaru, BRASIL | V.6 N.10 [2020] 
ou no ambiente de trabalho, o domínio e o preparo em torno dessas tecnologias.

A participação ocorreu de forma voluntária através de convites enviados aos participantes via e-mails ou pelo aplicativo WhatsApp e todos foram informados de que não seria necessário a identificação, uma vez que o foco do questionário era a perspectivas das novas tecnologias na aprendizagem.

\section{Resultados e Discussões}

As informações apresentadas a seguir são os resultados do processo da pesquisa. Para entender o perfil dos entrevistados, foi realizada a contagem das respostas e o agrupamento em gráficos, constatando que:

A primeira pergunta do questionário é referente a faixa etária dos professores, pois as experiências se diferenciam conforme às épocas. A pesquisa indicou que $25 \%$ têm idades entre 25 a 35 anos, $50 \%$ têm entre 35 a 45 anos, $25 \%$ têm idades entre 45 a 55 anos.

\section{Faixa Etária}

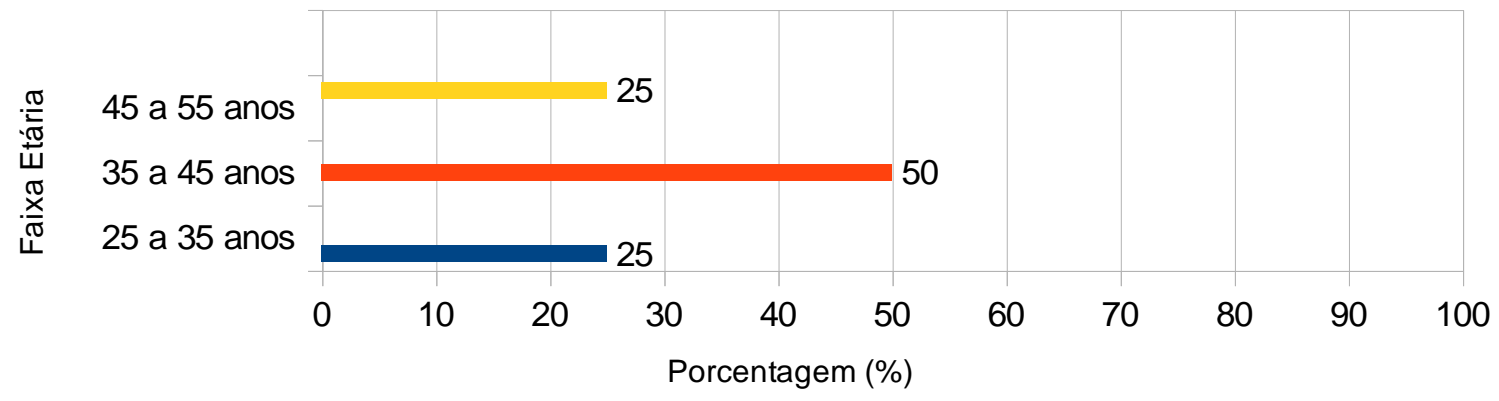

Fonte: Dados da pesquisa feita com os docentes.

Quanto ao gênero dos entrevistados $75 \%$ deles são do gênero feminino e $25 \%$ do gênero masculino.

REVISTA interritórios
Interritórios | Revista de Educação Universidade Federal de Pernambuco, Caruaru, BRASIL | V.6 N.10 [2020] 


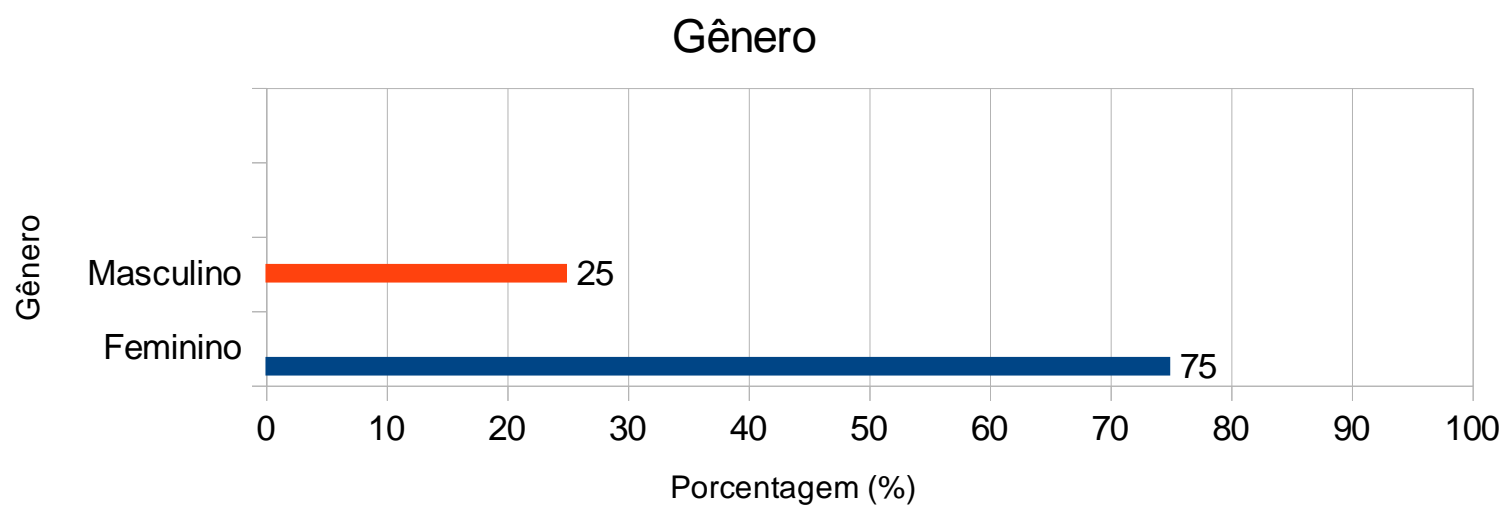

Fonte: Dados da pesquisa feita com os docentes.

Quando interrogados quanto ao grau de escolaridade, todos responderam ter cursado alguma especialização, porém nenhum mestrado.

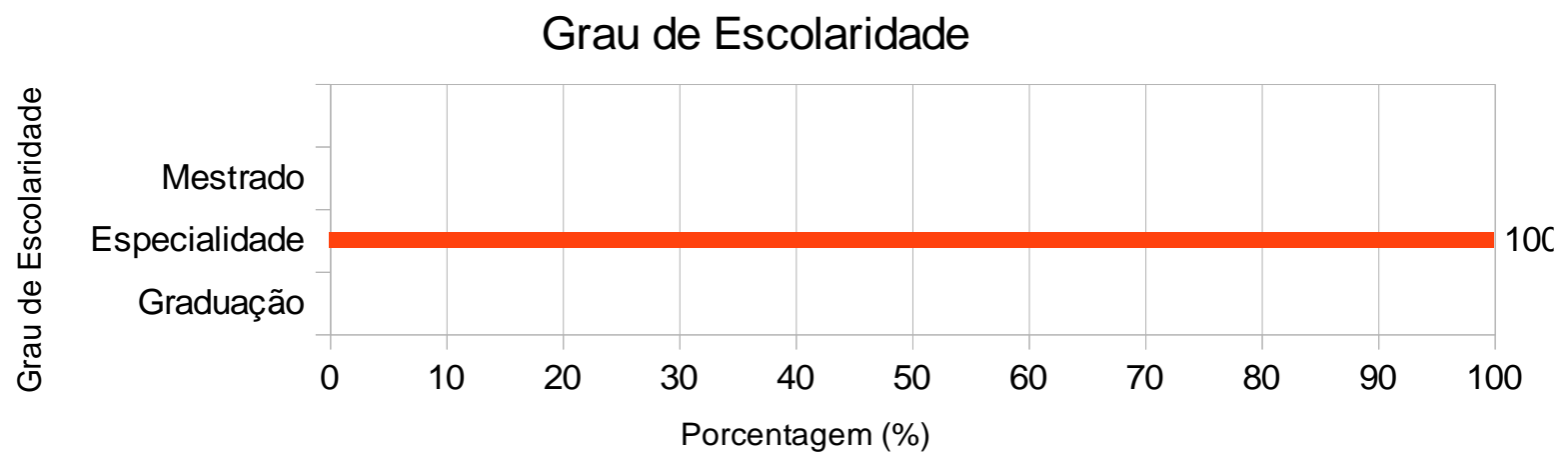

Fonte: Dados da pesquisa feita com os docentes.

Perguntou-se também aos professores o grau que lecionam, $62,5 \%$ lecionam no Ensino Fundamental e Médio, apenas 12,5 \% atuando no Ensino Fundamental e 25\% no Ensino Médio. 


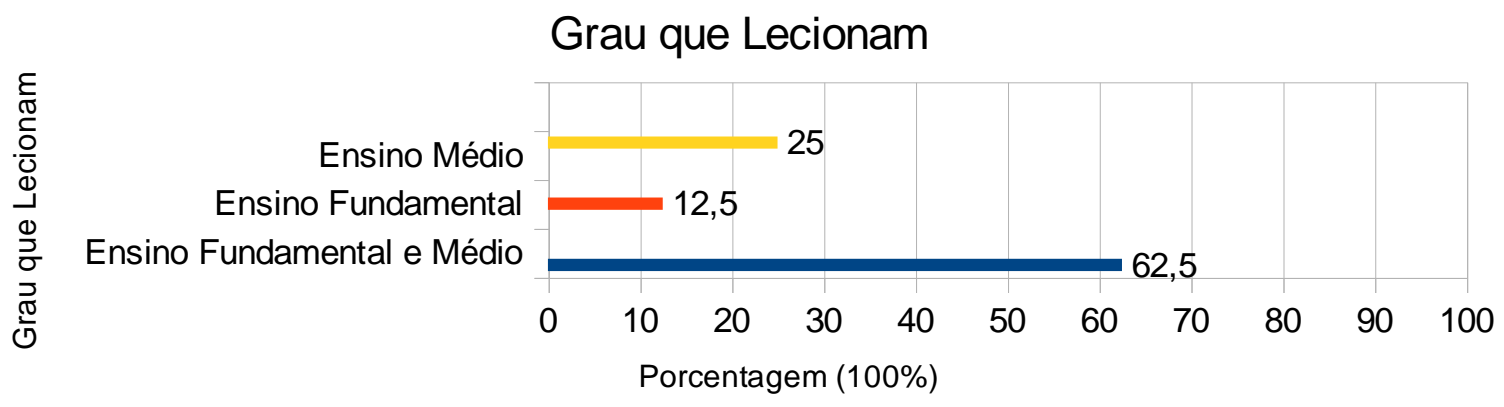

Fonte: Dados da pesquisa feita com os docentes.

A Internet tem grande repercussão em todo o mundo como ferramenta facilitadora, e conforme indicou a pesquisa, a maioria dos professores entrevistados têm o costume de utilizar esse valioso recurso. $62,5 \%$ passam em média 5 horas por dia acessando e o restante, $37,5 \%$ acessam durante 3 horas por dia.

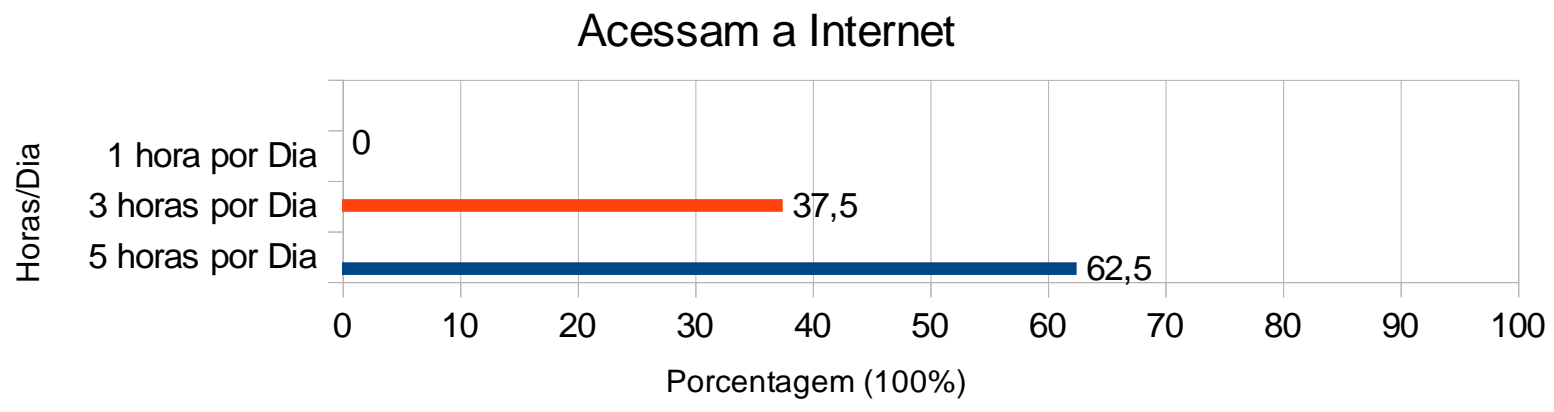

Fonte: Dados da pesquisa feita com os docentes.

Quanto as fontes de informação usadas por seus alunos, 12,5\% acreditam que usam livros, jornais e revistas e 87,5 a Internet, seja pelo aparelho celular, computador ou tablets.

REVISTA interritórios
Interritórios | Revista de Educação Universidade Federal de Pernambuco, Caruaru, BRASIL | V.6 N.10 [2020] 


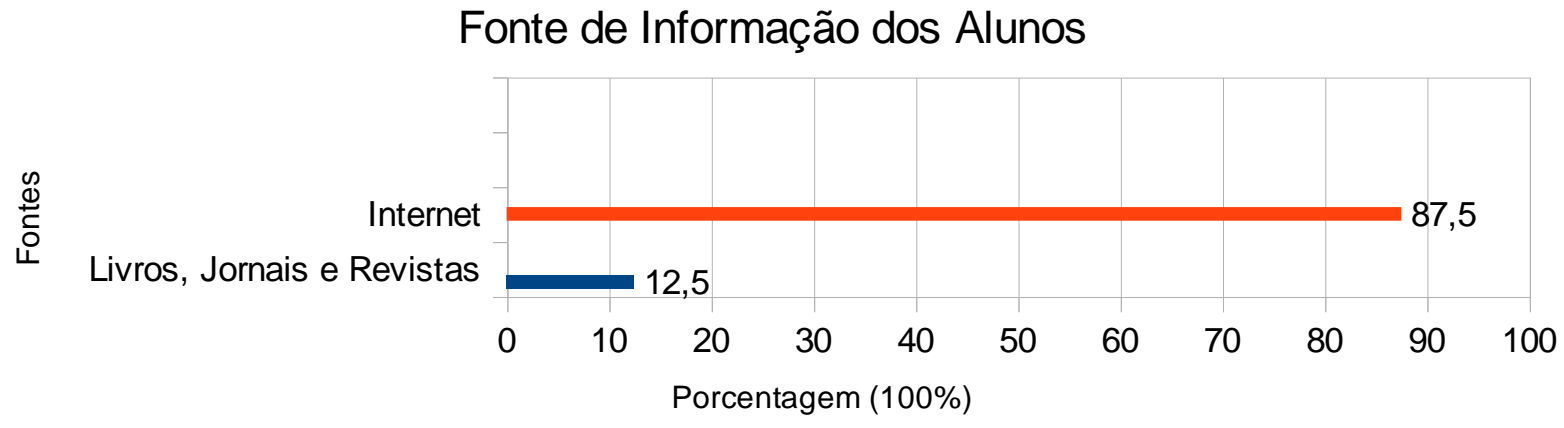

Fonte: Dados da pesquisa feita com os docentes.

Os que consideram o uso das TIC's necessário foram $87,5 \%$ e apenas $12,5 \%$ pouco necessário.

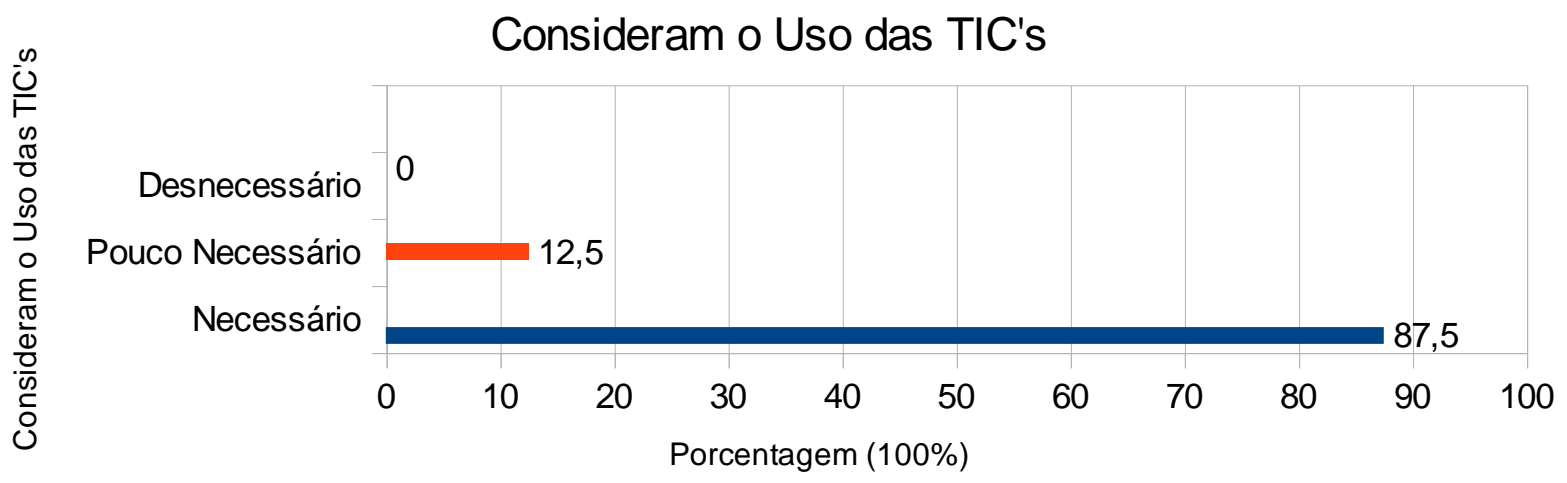

Fonte: Dados da pesquisa feita com os docentes

Quando indagados sobre a frequência do uso de algum recurso tecnológico, 50\% dos participantes da pesquisa utilizam muito algum recurso, $25 \%$ utilizam pouco e $25 \%$ quase nunca utilizam tais recursos. 
Frequência de Uso das TIC's

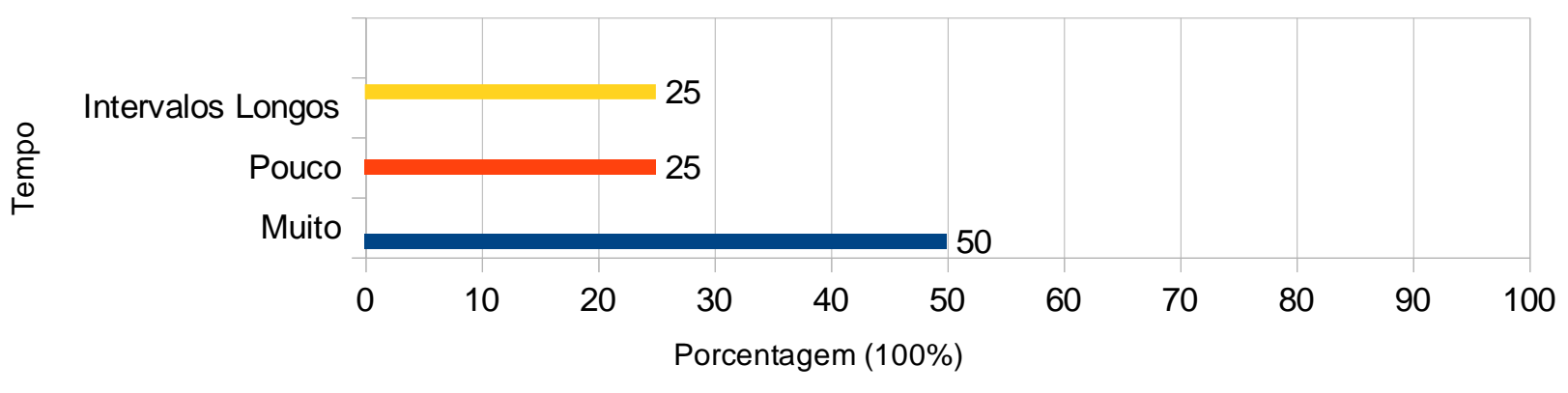

Fonte: Dados da pesquisa feita com os docentes.

Referente a essa interrogativa, sobre a frequência que eram utilizados algum recurso tecnológico em sala de aula e a inclusão das TIC's no contexto escolar, muitos dos professores citaram, além do que foi questionado, sobre a dificuldade com o número de aulas e quantidade de conteúdos a serem trabalhados. Destacaram que o tempo fica racionado para trabalhar todos os conteúdos utilizando os recursos.

A última pergunta do questionário, indagou-se sobre o domínio no uso das tecnologias. Apenas um (12,5\%) dos entrevistados possui curso para trabalhar com as TIC's em sala de aula, $62,5 \%$ dos professores aprenderam na prática, mas ressaltam quem não possuem dificuldades e o restante, $25 \%$, algumas vezes precisam de auxílio para trabalhar com as TIC's.

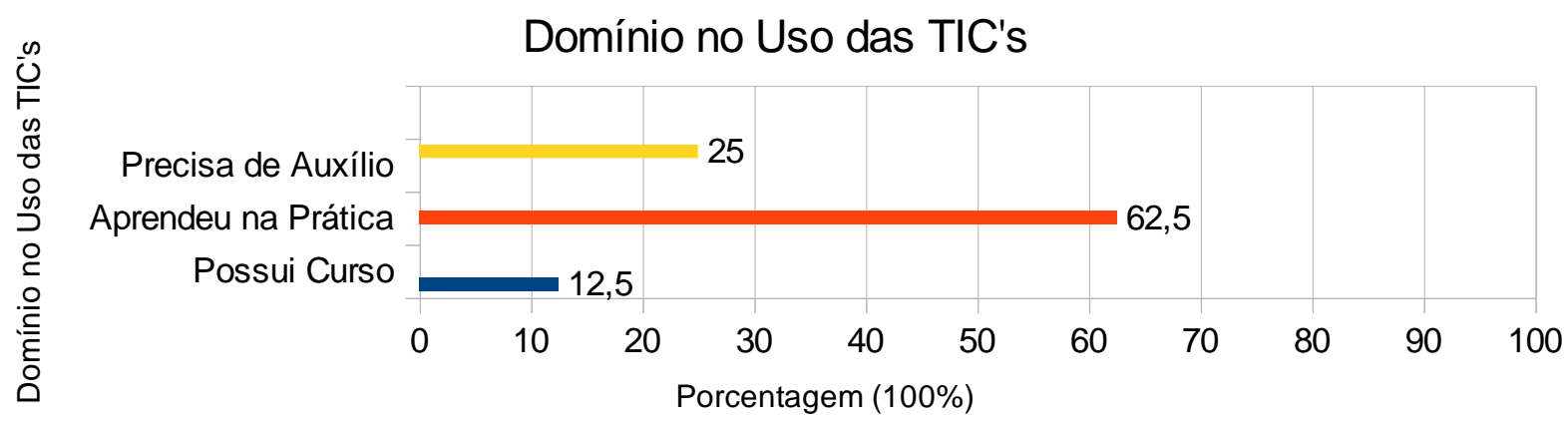

Fonte: Dados da pesquisa feita com os docentes.

Os que responderam que conseguem manusear os equipamentos sem dificuldades e que aprenderam na prática, citaram aparelhos mais conhecidos como

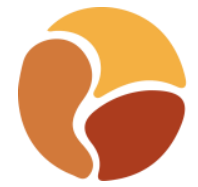

REVISTA interritórios

Interritórios | Revista de Educação Universidade Federal de Pernambuco, Caruaru, BRASIL | V.6 N.10 [2020] 
projetor de slides ou Datashow, retroprojetor, aparelho de DVD e CD, computador, tablets, porém afirmaram que possuem dificuldades quando a questão é, por exemplo, aplicativos ou softwares.

A análise das respostas dos voluntários entrevistados aponta para a fragilidade da inserção das TIC's nas práticas pedagógicas por vários fatores. Apesar de cem por cento dos entrevistados terem alguma especialização, a falta de domínio no uso das tecnologias ainda se faz presente e afeta alguns professores pesquisados. Apresenta-se como dificuldade especialmente para aqueles docentes que já atuam no ensino a mais tempo e sentem-se confortável com a forma de ensinar que sempre os acompanharam. Dessa forma, é perceptível que o professor realmente precisa encontrar-se mais capacitado para a pós-modernidade.

O profissional da educação necessita ter as habilidades suficientes para utilizar os recursos tecnológicos, caso contrário será impossível oferecer a formação integral do educando através da junção entre as novas tecnologias e as práticas pedagógicas. Portanto, cabe a cada envolvido no ambiente escolar assumir seu papel e buscar meios de superação dos vários obstáculos existentes.

\section{Considerações Finais}

Levando em consideração que os avanços tecnológicos são algo inevitável, em algum momento as escolas e os professores terão que se adaptar de alguma forma a tais modernidades. Vendo tal processo como mais um desafio que deve ser superado por todos que fazem parte da organização educacional, é possível pensar no uso das Novas Tecnologias de Informação e Comunicação de forma a positivar os estudos das novas gerações.

Assim, o que apresentamos nesse trabalho foram algumas observações sobre a resistência de alguns educadores ao uso das novas tecnologias, junto a falta de preparo diante desse desafio e a função das escolas nos dias de hoje com presença de ferramentas tecnológicos no ambiente escolar. Durante a pesquisa todas as menções nos fizeram pensar que, fazer uso das novas tecnologias não é o mesmo que fazer delas uma ferramenta para a aprendizagem do aluno. Apesar da maioria dos docentes voluntários entrevistados fazerem uso de alguma Tecnologia de Comunicação e Informação, ainda se pode e deve-se explorar muito mais tais recursos para o total sucesso e satisfação na educação.

Diante do que foi exposto e discutido, podemos concluir que o primeiro passo para

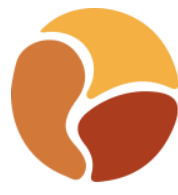

REVISTA

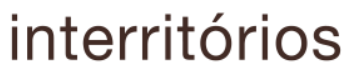

Interritórios | Revista de Educação Universidade Federal de Pernambuco, Caruaru, BRASIL | V.6 N.10 [2020] 
implantar as novas Tecnologias de Informação e Comunicação no ambiente escolar é verificar qual tipo de tecnologia mais se adapta ao contexto da escola, dos professores e dos alunos ali presentes. Foi possível entender que nem toda tecnologia é de fato nova, mas que algumas, mesmo não atuais, podem fazer a diferença no cotidiano do aluno e em seu aprendizado quando usadas com dinamismo.

O segundo passo, seria o treinamento de professores que ainda se apoiam apenas em métodos ultrapassados e que por isso veem as novas tecnologias como algo negativo, quando na verdade seu uso causam retornos positivos no futuro dos educandos, que percebem como os educadores se preocupam em tornar a escola um ambiente mais moderno dentro da atual realidade.

Dessa forma, é viável que as novas Tecnologias de Informação e Comunicação estejam presentes na vida escolar em todos os contextos possíveis, ou seja, desde o coordenador pedagógico que usa um computador para organizar os horários, passando pelo professor que usa a mesma ferramenta para digitar a prova do dia ou lançar as notas, chegando finalmente ao aluno que usa o computador, celular ou tablets para fazer pesquisas educativas na Internet.

\section{REFERÊNCIAS}

ALMEIDA, Fernando José; VALENTE, José Amando. Visão Analítica da Informática na Educação do Brasil: A Questão da Formação do Professor. 2008, p.05. Disponível em: http://www.lbd.dcc.ufmg.br/colecoes/rbie/1/1/004.pdf. Acessado em: 15 ago. 2019.

BELLONI, Maria Luiza. O que é mídia-educação? Campinas: Autores Associados. 2001.

BRASIL, MEC / SEED. Programa Nacional de Informática na Educação - Proinfo. Brasília, 1998, p.140.

BRASIL. Ministério da Educação. Diretrizes Curriculares Nacionais para a Formação de Professores da Educação Básica. 2002. Disponível em: http://portal.mec.gov.br/pet/323secretarias-112877938/orgaos-vinculados-82187207/12861-formacao-superior-para-adocencia-na-educacao-basica. Acessado em: 14 ago. 2019.

BRASÍLIA. Parâmetros curriculares nacionais do terceiro e quarto ciclo ensino fundamental: introdução aos parâmetros curriculares nacionais. Secretaria de Educação Fundamental. Brasília: Ministério da Educação, 1998.

CARVALHO, Rosita Edler. Educação Inclusiva com os Pingos nos is. Porto Alegre: Editora Mediação, 2004, p.113.

REVISTA interritórios
Interritórios | Revista de Educação Universidade Federal de Pernambuco, Caruaru, BRASIL | V.6 N.10 [2020] 
CAVALCANTE, Marcio Balbino. A educação frente as novas tecnologias: Perspectivas e desafios. 2012. Disponível em: https://escoladrxavierdealmeida.blogspot.com.br/2012/02/educacaofrente-as-novas-tecnologias.html. Acessado em: 13 ago. 2019.

FANTIN, Mônica. Alfabetização Midiática na Escola. VII Seminário Mídia, educação e Leitura. 10 a 13 de julho. Campinas, SP, 2007, p. 04. Disponível em: http://www.alb.com.br/anais16/sem05pdf/sm05ss15 06.pdf. Acessado em: 12 ago. de 2019.

KENSKI, Vani Moreira. Tecnologias e Ensino Presencial e a Distância. 9 ed., Campinas, SP: Papirus, 2012.

LÉVY, Pierre. Cibercultura. São Paulo: Editora 34, 2005, p. 172.

MARTINHO, T \& POMBO, L. Potencialidades das TIC's em ensino das ciências naturais - um estudo de caso. Revista electrónica de Enseñanza de las ciências. Granada, Espanha. 2009. p.528.

MORAN, José Manuel; MASETTO, Marcos; BEHRENS, Maria Aparecida. Novas tecnologias e mediação pedagógica. 4 ed. São Paulo: Papirus, 2003, p.153 - p.142.

NISKIER, Arnaldo. Tecnologia educacional: uma visão política. Petrópolis, RJ: Vozes, 1993.

NUNES, Cesar; GALLOTTA, Alexandre. Objetos de Aprendizagem a serviço do professor. 2011. Disponível em: http://www.microsoft.com/brasil/educacao/parceiro/objeto texto.mspx. Acessado em: 11 ago 2019.

PAPERT, Seymour. A máquina das Crianças. São Paulo: Brasiliense. 1985. SÃO PAULO. Pesquisa sobre o uso das tecnologias de informação e comunicação nas escolas brasileiras: TIC Educação. 2013 [livro eletrônico]. Coordenação executiva e editorial, Alexandre F. Barbosa / tradução / 1. Ed. São Paulo: Comitê Gestor da Internet no Brasil, 2014. 